\title{
Revizyon kalça artroplastisinde asetabular kemik kaybı sınıflandırması ve rekonstrüksiyon seçenekleri
}

\author{
Acetabular bone loss classification and reconstruction options in \\ revision hip arthroplasty
}

\author{
Ömür Çağlar, Zirvecan Güneş
}

Hacettepe Üniversitesi Tıp Fakültesi, Ortopedi ve Travmatoloji Ana Bilim Dalı, Ankara

\begin{abstract}
Son yıllarda, yapılan primer total kalça artroplastisi sayısı ve bununla doğru orantılı bir şekilde revizyon kalça artroplastisi sayısı da giderek artmaktadır. Revizyon kalça artroplastisinde asetabular kemik defektlerini doğru bir şekilde değerlendirmek ve cerrahi olarak yönetebilmek son derece önemlidir. Ameliyat öncesinde hastanın uygun bir şekilde değerlendirilmesi ve planlama yapılması, başarılı sonuç için olmazsa olmazdır. Hastadan ayrıntılı öykü alınmalı, fizik muayene yapılmalı ve periprostetik enfeksiyonu ekarte etmek için laboratuvar tetkikleri uygulanmalıdır. Tekniğe uygun çekilen direkt radyografiler, asetabular kemik kayıplarının radyolojik değerlendirilmesinde kritik öneme sahiptir. Ayrıca bilgisayarlı tomografi ile asetabular kemik defektinin yapısını ayrıntılı bir şekilde değerlendirmek ve üç boyutlu yapısını anlamak mümkündür. Asetabular kemik kayıpları sınıflandırmaları ile, kemik kayıpları tanımlanmakta ve olası cerrahi tedavi seçenekleri belirlenmektedir. Revizyon kalça artroplastisinde her rekonstrüksiyon seçeneğinin, avantaj ve dezavantajları olsa da temel prensipleri benzerdir ve amaçları stabil bir yapı elde etmektir. Cerrahi tedavi seçenekleri arasında; impaksiyon greftleme, yapısal allogreft ile rekonstrüksiyon, çimentosuz hemisferik asetabular komponent ile rekonstrüksiyon, modüler poröz metal augmentler, halka-kafes ile rekonstrüksiyon, kap-kafes sistemleri, trafilange kap ile rekonstrüksiyon gibi seçenekler sayılabilir.
\end{abstract}

Anahtar sözcükler: revizyon total kalça artroplastisi; asetabulum; asetabular kemik defektleri

\begin{abstract}
The number of primary total hip arthroplasty performed in recent years has been increasing. As a result, the number of revision hip arthroplasty is increasing in direct proportion. It is extremely important to accurately evaluate and surgically manage acetabular bone defects in revision hip arthroplasty. Evaluation and planning of the patient properly before the operation is essential for a successful outcome. A detailed history should be taken from the patient, physical examination should be done, and laboratory tests should be performed to rule out periprosthetic infection. Direct radiographs taken in accordance with the technique have a critical importance in the radiological evaluation of acetabular bone losses. In addition, it is possible to evaluate the structure of the acetabular bone defect in detail and to understand its 3-dimensional structure with computed tomography. Bone losses are defined by acetabular bone loss classifications, and possible surgical treatment options are determined. Although each reconstruction option has advantages and disadvantages in revision hip arthroplasty, its basic principles are similar and their aim is to achieve a stable structure. Surgical treatment options include; impaction grafting, reconstruction with structural allograft, reconstruction with cementless hemispheric acetabular component, modular porous metal augments, ring-cage reconstruction, cup-cage systems, and trafilange cup reconstruction.
\end{abstract}

Key words: revision total hip arthroplasty; acetabulum; acetabular bone losses

beklenmektedir. ${ }^{[4]}$ Modern artroplasti teknikleri ve implant tasarımları, primer kalça artoplastisi ameliyatının uzun dönem sonuçlarını şimdiye kadar hiç olmadığı kadar iyileştirmiştir. Gerçekleştirilen toplam artroplastilerin sayısındaki büyük artış göz önüne alındığında, revizyon ameliyatlarının yıllık yükü de her geçen yıl artmaktadır. Asetabular komponent revizyonu için başlıca endikasyonlar; aseptik gevşeme, kalça instabilitesi, periprostetik kırık ve periprostetik enfeksiyondur. ${ }^{[5,6]}$ İmplante edilen taşıyıcı yüzeylerde meydana gelen aşınma ve yıpranma, ça artoplastisi sayısının günümüze göre iki kat artması

iletişim / Contact: Prof. Dr. Ömür Çağlar • E-posta / E-mail: ocaglar@hacettepe.edu.tr

ORCID iD: Ömür Çağlar, 0000-0002-0346-8528 • Zirvecan Güneş, 0000-0001-7833-0331 
kalça eklemi çevresine partikül salınımına yol açar. Bu durum, doku reaksiyonlarına ve periprostetik kemikte osteolize, en sonunda da komponentlerin aseptik gevşemesine sebep olur; aseptik gevşeme uygun zamanda tedavi edilmediği takdirde de, protez çevresinde büyük ve revizyonu zor kemik defektleri gelişebilir. ${ }^{[7]}$ Revizyon artroplastisi sırasında karşılaşılan asetabular kemik defektleri, hafif veya şiddetli olabilmektedir. Azalmış asetabular kemik stoğu, asetabulumun ön ve arka kolonlarında azalan destek ve değişen derecelerdeki medial duvar ve asetabular çatı yetmezliği, revizyon ameliyatında cerrah için teknik zorluk yaratır. Ayrıca, asetabular kemik kaybı ilerledikçe, asetabular komponentin ve tespit vidalarının yerleştirilmesi giderek zorlaşır. Bu durumun sonucunda kemik ve komponent arasındaki yetersiz tespit, entegrasyonunun (bütünleşmenin) ve uzun sürede biyolojik tespitin başarısızlığına sebep olur. Asetabular kemik defektleri için literatürde çok sayıda cerrahi tedavi tanımlanmasına rağmen, tedavi seçeneklerinin birbirine olan üstünlüğü ile ilgili halen yeterli bilgi bulunmamaktadır. ${ }^{[8]}$ Asetabular kemik defektinin durumu ve miktarına göre rekonstrüksiyon seçenekleri değişmekle birlikte, her bir rekonstrüksiyon seçeneğinin bir diğerine göre avantaj ve dezavantajları bulunur. Bu yazımızda, revizyon kalça artroplastisinde asetabular kemik defektleri ve rekonstrüksiyon seçeneklerinin kapsamlı bir şekilde anlaşılması için; kemik defektlerinin sınıflandırmasından, mevcut cerrahi tedavi seçeneklerinden, ameliyat öncesi planlamadan ve karşılaşılan komplikasyonlardan bahsedeceğiz.

\section{AMELIYAT ÖNCESI DEĞERLENDIRME}

\section{Hikâye - Fizik Muayene - Laboratuvar}

Asetabular komponent revizyonu planlanan her hastada ameliyat öncesi değerlendirme kritik öneme sahiptir ve mutlaka ayrıntılı bir öykü alınması gerekir. Hastanın geçirdiği bütün ameliyatlar ve bu ameliyatlar sırasında gelişen komplikasyonlar ayrıntılı bir şekilde not edilmelidir. Ağrı, revizyon gerektiren en yaygın şikâyettir ve öyküde, ağrının yeri, tipi, karakteri, süresi, hangi zamanlarda arttığı (sadece gece ağrısı, hareket ile ağrı) ve ağrıya eşlik eden bulgular sorgulanmalıdır. Ameliyat sonrası semptomların başlama zamanı ve süresi tanı için yönlendiricidir. Erken dönemde meydana gelen ağrılarda, özellikle kalça instabilitesi ve enfeksiyon akla gelmeli, enfeksiyon mutlaka ekarte edilmelidir. Serum eritrosit sedimentasyon hızı (normal, <20 $\mathrm{mg} / \mathrm{dl}$ ) ve C-reaktif protein (CRP, normal, $<10 \mathrm{mg} / \mathrm{dl}$ ) tetkik edilmelidir. Sedimentasyon ve CRP düzeyinde artış olması durumunda eklem aspirasyonu uygulanmalı, alınan örnekler kültüre gönderilmeli ve sinovyal sıvı hücre analizi yapılmalıdır. ${ }^{[9]}$ Sinovyal sıvı analizinde, özellikle 3000 ve üzeri lökosit sayısı ve $\% 60$ 'tan fazla nötrofil oranı enfeksiyon açısından şüpheli kabul edilmelidir. ${ }^{[10,11]}$ Fizik muayenede; hastanın genel durumuna bakılmalı, lumbosakral omurga muayenesi yapılmalı ve bilateral alt ekstremitenin ayrıntılı olarak değerlendirilmesi gerekmektedir. Ayrıntılı motor (aktif kalça abduksiyonu), duyusal ve vasküler muayene yapılmalıdır. Hastanın yürüyüş durumu (en sık, antaljik yürüyüş veya abduktor kas güçsüzlüğüne ikincil gelişen Trendelenburg yürüyüşü) ve alt ekstremite uzunluk eşitsizliği de değerlendirilmelidir. ${ }^{[12]}$ Ayrıca sigara ve malnütrisyon yara yeri sorunları ve enfeksiyon ile ilişkili modifiye edilebilir risk faktörleri olduğundan dolayı, uygun hastalarda ameliyat öncesi değerlendirmenin bir parçası olarak nikotin seviyesi ve nütrisyonel değerlere de bakılabilir.

\section{Radyografik Değerlendirme}

Asetabular kemik defektlerinin ayrıntılı olarak değerlendirilmesi için ameliyat öncesi ayrıntılı radyografik inceleme yapılmalıdır. Asetabular kemik kaybının yeri ve şiddeti, yapılması gereken asetabular revizyon cerrahisini, kullanılacak implantların türünü ve başarıyı belirler. Asetabular revizyon cerrahisinin ameliyat öncesi görüntüleme değerlendirmesinde rutin olarak standart anteroposterior (AP) pelvis ve tam uzunlukta iki yönlü femur grafileri görülmelidir. Anteroposterior pelvis grafisinde röntgen, bacak uzunluğunun değerlendirilmesine olanak verecek şekilde simfizis pubis üzerinde ortalanmalı ve koksiks ile hizalanmalıdır. Çekilen grafilerde protez tam boyutlu olarak görülmelidir. Judet grafileri ise implant kemik ara yüzünü daha ayrıntılı görmek ve asetabulumun ön (obturator oblik) ve arka (iliak oblik) kolonlarındaki defektleri tespit etmek için yararlıdır. [13] Ayrıca birçok çalışmada, direkt radyografiler ile osteolitik lezyonun boyutunun tam olarak anlaşılamadığı, olduğundan daha küçük olarak görüldüğü hatta küçük osteolitik alanların tespit dahi edilemediği sonucuna varılmıştır. ${ }^{[14,15]}$ Bununla birlikte, total kalça artroplastisi uygulanmış hastalarda ameliyat sonrası düzenli aralıklarla çekilmiş seri radyografilerin, asetabular kemik kayıplarının değerlendirilmesinde önemli olduğu kabul edilmektedir. Seri radyografilerde, hastalık ilerlemesinin yanı sıra, asetabular komponentin stabilitesindeki değişiklikler de zaman içinde görülebilir. Bu nedenle, hastanın ilk ameliyat sonrası görüntüsünden son takip görüntüsüne kadar tüm eski radyografik görüntülerini incelemek gerekir. Sadece direkt radyografinin osteolizi tespit etmedeki hassasiyeti çoğunlukla yeterli olmamaktadır. Bu nedenle, direkt radyografiye göre daha yüksek maliyetli ve daha yüksek radyasyon maruziyetine neden olmasına rağmen, bilgisayarlı tomografi (BT) asetabular revizyon uygulanacak hastalarda bize ayrıntılı bilgi 
sağlar. ${ }^{[14,16]}$ Bilgisayarlı tomografi, periasetabular osteolizin yerini, miktarını ve ilişkili kemik defektlerini ortopedik cerraha daha ayrıntılı veriler ile sunabilen, üç boyutlu da olabilen görüntüler verir. ${ }^{[17]}$ Ayrıca BT, direkt radyografilere kıyasla, hastanın femoral ve asetabular komponentlerinin versiyonunun daha kesin bir değerlendirmesinin yapılmasına olanak sağlar. ${ }^{[18]}$ Manyetik rezonans (MR) görüntüleme kemik defektlerini incelemede BT'ye göre daha yetersizdir, ancak advers yumuşak doku reaksiyonlarını (psödotümör, metal birikimler) görüntülemek için MARS (Metal Artifact Reduction Sequences) tercih edilebilir. ${ }^{[16]}$ Ek olarak, asetabular komponentte medial migrasyon varsa, özellikle kontrastlı BT ve anjiyografi ile komponentin pelvik damarlar, üreter ve mesaneye olan yakınlığının değerlendirilmesi mümkündür. ${ }^{[19-21]}$

\section{CERRAHI PLANLAMA}

\section{İmplantlar}

Ameliyat öncesi değerlendirmede hastanın mevcut implantlarının doğru şekilde tespit edilmesi ve gerekirse implanta özgü çıkarma setlerinin ameliyat sırasında hazır olacak şekilde bulundurulması önemlidir. Ayrıca, hastanın implantlarının önceden bilinmesi olası bir ameliyat sırasında oluşabilecek komplikasyonun sınırlandırılmasına, ameliyat süresinin azaltılmasına ve hastanın cerrahi sonuçlarının optimizasyonuna yardımcı olacaktır.

\section{Cerrahi Yaklaşım}

Revizyon ameliyatı için yaklaşım, cerrah deneyimi sayesinde, asetabular-femoral defektin büyüklüğü ve yeri ile bozulmuş pelvik anatominin iyi anlaşılmasıyla belirlenir. Revizyon cerrahisi sırasında, posterolateral yaklaşım en sık kullanılan ve görece en yararlı yaklaşım olarak tanımlanmıştır. Posterolateral yaklaşımda, asetabulum ve iliak kanadı çepeçevre çok iyi bir şekilde görmek mümkündür. Çoğu rekonstrüksiyon posterolateral yaklaşım ile yapılmasına karşın, femur mobilizasyonunun zor olduğu durumlarda veya daha geniş bir görüş elde etmek için, femoral osteotomiler de uygulanabilir. Trokanterik kaydırma osteotomisi, genişletilmiş trokanterik osteotomi ve Wagner osteotomisi gibi birçok femoral osteotomi tanımlanmıştır. ${ }^{[22]}$ Trokanterik kaydırma osteotomisi, özellikle superior kalça kapsülünü daha iyi görmek için tercih edilen osteotomi tipidir. Osteotomi, vastus lateralis ve gluteus medius kaslarını osteotomi uygulanan proksimal fragmandan ayırmadan uygulanır. Abduktor kas grubu korunduğundan dolayı, abduktor kas güçsüzlüğü ve proksimal fragmanın migrasyonu çok az görülür. Ayrıca, kemiğin kan dolaşımı korunduğundan dolayı iyi ve hızlı bir kaynama sağlanmış olur. Orijinal Wagner osteotomisi, proksimal femurun anterior $1 / 3$ 'ü ve abduktor kas grubunun anterior yarısı kullanılarak uygulanır. Daha sonra bu yaklaşım femurun proksimal lateral $1 / 3$ 'ü ve devamındaki abduktor kas grubu kullanılacak şekilde modifiye edilmiş ve bu yaklaşıma genişletilmiş trokanterik osteotomi denilmiştir. ${ }^{[23]}$ Genişletilmiş trokanterik osteotomi ise özellikle femoral komponentin çıkarılmasını kolaylaştıran bir yöntemdir.

\section{Asetabular Kemik Kaybı Sınıflandırması}

Revizyon kalça artoplastisi uygulanacak hastalarda asetabular kemik defektleri değerlendirilmesi ve bir standart oluşturulması adına bir sınıflandırma gereksinimi doğmuştur. ${ }^{[24]}$ Total kalça artroplastisinde asetabular kemik defektleri için birçok sınıflandırma tanımlanmıştır. ${ }^{[25-30]}$ Sınıflandırma sistemleri arasında benzerlikler olsa da, her birinin kemik defektlerini hafiften ağıra doğru sıralayan kendine özgü yöntemleri vardır. Günümüzde asetabular kemik defektlerinde en sık kullanılan sınıflandırma sistemi Paprosky sınıflandırmasıdır. ${ }^{[29]}$ Bu sınıflandırma, kemik kaybının yeri ve büyüklüğünün değerlendirmesinde yararlı olmasının yanı sıra, stabil bir asetabular komponent tespiti için hangi tip rekonstrüksiyon gerektiği konusunda da ortopedi ve travmatoloji uzmanları için yönlendirici olmaktadır.

\section{Amerikan Ortopedi Cerrahları Akademisi (AAOS) sınıflaması}

D'Antonio ve ark. tarafından 1989 yılında geliştirilen bir sınıflamadır. ${ }^{[26]}$ Segmenter, kaviter veya kombine defektler olmak üzere üç alt tipe ayrılır (Tablo 1). Tip 1 defektler, segmental defektleri ifade eder ve periferal (1A) ya da santral (1B) segmental defektler olmak üzere ikiye ayrılır. Periferal kemik kayıpla$\mathrm{rı}$, bulunduğu yere göre, superior, anterior ve posterior olmak üzere ifade edilebilir. Santral defektler, medial asetabular duvar bütünlüğünün bozulduğu

Tablo 1. Asetabular kemik defektleri için AAOS sınıflamasi ${ }^{[26]}$

\begin{tabular}{cl}
\hline Tip & Tanım \\
\hline 1 & Segmental defekt \\
2 & Kaviter defekt \\
3 & Kombine segmental ve kaviter defekt \\
4 & Pelvik devamsızlık \\
4A & Hafif kemik defekti ile birlikte pelvik devamsızlık \\
4B & Ağır kemik defekti ile birlikte pelvik devamsızlık \\
4C & Pelvik radyasyon maruziyeti ile birlikte pelvik devamsızlık \\
5 & Kalça artrodezi
\end{tabular}


asetabulum ortasında görülen defektlerdir. Kaviter defektler ise tip 2 defektler olarak isimlendirilir; tip 1 'de olduğu gibi periferal ve santral defektler olmak üzere (tip $2 \mathrm{~A}$ ve tip $2 \mathrm{~B}$ ) ikiye ayrılır. Tip 2 periferal defektler, yine tip 1'de olduğu gibi, defektin bulunduğu yere göre superior, anterior ve posterior defektler olarak isimlendirilir. Tip 2 santral defektlerde, tip 1 'den farklı olarak, medial asetabular duvar bütünlügü korunmuştur. Tip 3 defektler, kaviter ve segmental defektlerin bir arada bulunduğu kombine defektleri ifade eder. Tip 4 defektler pelvik devamsızlığın olduğu, tip 5 defektler de kalça artrodezinin görüldüğü alt tiplerdir. Bu sınıflandırma kendi içinde kolay bir anlatıma sahipken, defektin büyüklüğü açısından kantitatif bir ifade vermemesi ve bir tedavi önerisi getirmemesi önemli dezavantajlarındandır. Ayrıca, yapılan çalışmalarda AAOS sınıflamasının gözlemciler arası güvenilirliğinin düşük olduğu gösterilmiştir. ${ }^{[31,32]}$

\section{Paprosky sınıflaması}

Günümüzde asetabular kemik kayıpları için en yaygın olarak kullanılan sınıflama sistemi Paprosky sınıflamasıdır. 1994 yılında Paprosky ve ark. tarafından geliştirilmiş olan bu sınıflandırma, ameliyat öncesi ve ameliyat sırasında değerlendirilen defektin yeri ve büyüklüğü hakkında bize daha ayrıntılı bilgi vermekte ve buna göre bize tedavi önerileri sunmaktadır (Tablo 2). ${ }^{[29]}$ Radyolojik değerlendirmede; kalça rotasyon merkezinin migrasyonuna, iskion osteolizine, gözyaşı figürünün durumuna ve Kohler çizgisinin devamlılığına bakılır. Kalça rotasyon merkezinin migrasyonu, superior obturator çizgi referans alınarak değerlendirilir. Tip 1 defektlerde minimal kemik kaybı görülür ve asetabulumun hemisferik şekli korunmuştur; anterior ve posterior kolonlar sağlamdır ve komponentin $\% 70$ 'i ana kemik tarafindan desteklenerek iyi bir komponent stabilitesi elde edilebilir. Tip 1 defeklerde çimentosuz poröz kaplı asetabular komponentler kullanılarak revizyon uygulanabilir. Tip 1'de kalça rotasyon merkezinde migrasyon, iskiumda ve gözyaşı figüründe osteoliz yoktur ve Kohler çizgisi intakttır. Tip 2 defektlerde asetabulum anterior ve posterior kolonları sağlamdır ve kendi içerisinde $2 \mathrm{~A}$, $2 \mathrm{~B}$ ve $2 \mathrm{C}$ olmak üzere üçe ayrılır. Destek yapıları bozulmadığından dolayı tip 2 defektlerin revizyonunda da asetabular vidalar ile stabilitesi artırılmış çimentosuz poröz kaplı hemisferik asetabular komponentler kullanılabilir. Tip 2A'da kalça rotasyon merkezinde $3 \mathrm{~cm}$ 'den daha az superomedial migrasyon görülürken, iskiumda ve gözyaşı figüründe osteoliz minimal, Kohler çizgisi intakttır. Tip 2B'de kalça rotasyon merkezinde $3 \mathrm{~cm}$ 'den daha az superolateral migrasyon görülürken, tip $2 \mathrm{~A}^{\prime}$ da olduğu gibi iskium ve gözyaşı figüründe osteoliz minimal, Kohler çizgisi intaktır. Tip 2C'de kalça rotasyon merkezinde $3 \mathrm{~cm}$ 'den daha az superior migrasyon görülür. İskiumda osteoliz minimalken, bundan farklı olarak, gözyaşı figüründe ileri derecede osteoliz vardır. Kohler çizgisi tip 2C'de de intakttır. Tip 3 defektlerde, anterior ve posterior kolonlardaki destek yapılar bozulduğundan dolayı, revizyon ameliyatı sırasında greft gereksinimi olmaktadır. Ayrıca bunlar, pelvik devamsızlık ile ilişsili olabilen kompleks defektlerdir. Tip 3 defektlerde kalça rotasyon merkezinin migrasyonu $3 \mathrm{~cm}$ 'den daha fazladır. İskium ve gözyaşı figüründe osteoliz ileri derecede görülür. Kohler çizigisinin intakt olup olmamasına göre tip $3 A$ ve tip $3 B$ olmak üzere ikiye ayrılır. Tip $3 A^{\prime}$ da Kohler çizgisi intakt iken, tip 3B'de Kohler çizgisinin bütünlügüü bozulmuştur. Tip $3 \mathrm{~A}$ defektlere superolateral migrasyon görülmesinden dolayı 'up and in', tip 3B defektlere superomedial migrasyondan dolayı 'up and out' defektler de denmektedir. Tip 3A defektlerde

Tablo 2. Asetabular kemik defektleri için Paprosky sınıflaması ${ }^{[29]}$

\begin{tabular}{|c|c|c|c|c|c|}
\hline Tip & Femur başı migrasyonu & İskial osteoliz & Kohler çizgisi & Gözyaşı figürü & Tedavi \\
\hline 1 & Yok & Yok & İntakt & İntakt & Çimentosuz hemisferik asetabular kap \\
\hline $2 \mathrm{~A}$ & Superior $<3 \mathrm{~cm}$ & Yok & İntakt & İntakt & Çimentosuz hemisferik asetabular kap \\
\hline 2B & Superolateral $<3 \mathrm{~cm}$ & Hafif & İntakt & İntakt & Çimentosuz hemisferik asetabular kap \\
\hline $2 \mathrm{C}$ & Medial $<3 \mathrm{~cm}$ & Hafif & Bozulmuş & Hafif-orta lizis & $\begin{array}{l}\text { Çimentosuz hemisferik asetabular kap ve } \\
\text { medial greftleme }\end{array}$ \\
\hline $3 A$ & 'Up and out' $>3 \mathrm{~cm}$ & Orta & İntakt & Hafif-orta lizis & $\begin{array}{l}\text { Çimentosuz hemisferik asetabular kap } \\
\pm \text { poröz metal augment/yapısal allogreft }\end{array}$ \\
\hline 3B & 'Up and in' $>3 \mathrm{~cm}$ & Ağır & Bozulmuş & Ağır lizis & $\begin{array}{l}\text { Çimentosuz hemisferik asetabular kap } \\
\pm \text { poröz metal augment/yapısal allogreft } \\
\pm \text { kap kafes rekonstrüksiyonu / triflange kap }\end{array}$ \\
\hline
\end{tabular}


asetabular rimde \%30-60 kemik kaybı görülürken, tip 3 B'de $\% 60$ ve üzeri kemik kaybı bulunmaktadır. Tip 3 defektlerde destek yapıların bozulmuş olmasından ve ileri derecede kemik kaybı görülmesinden dolayı, revizyon ameliyatında modüler poröz metal augmentler, yapısal allogreftler, rekonstrüksiyon kafesleri, çimentolu-çimentosuz asetabular komponentler veya bunların kombinasyonu kullanılmaktadır. ${ }^{[18]}$

\section{Ghanem üç nokta tespiti sınıflaması}

Ghanem ve ark. tarafindan 2020 yılında yayımlanan ve geliş̧tirilen bu sınıflamada, ameliyat sırasında asetabular kemik konfigürasyonu temel alınır. Asetabulum içinde üç nokta prensibine dayanarak komponentin yerleştirilip yerleştirilemeyeceğine bakılır. Tip 1 defektlerde asetabulum hemisferik bir yapıdadır ve üç nokta prensibine göre tespitin mümkün olduğu tiptir. Çimentosuz hemisferik komponent ile tespit mümkündür. Tip 2 defektlerde kaviter defektler olmasına rağmen asetabulumun genel yapısı korunmuş ve üç nokta prensibine göre tespit mümkündür. Defektin büyüklügüne göre metal augmentler ve çimentosuz asetabular komponentler ile tespit mümkündür. Tip 3 defektlerde, ağır kemik defekti olmasından dolayı asetabulumun hemisferik yapısı tamamen bozulmuştur. Üç nokta prensibine göre komponent tespiti mümkün değildir. Kap-kafes rekonstrüksiyonu ile revizyon önerilir. Tip 4 defektlerde, pelvik devamsızlıkla birlikte ileri derecede kemik kaybı bulunmaktadır. Kişiye özgü üretilen pelvik asetabular komponentler ile tespit önerilir. ${ }^{[18]}$

\section{Asetabular Komponentlerin Çıkarılması}

Asetabular komponent revizyonunun gerekli olduğu durumlarda, komponentin en az miktarda ek kemik kaybı ile çıkarılması, ana kemik stoğunun korunması açısından önemlidir. Komponentin güvenli bir şekilde çıkarılabilmesi için asetabulumun çepeçevre görülmesi gerekir. Komponent stabilitesi, asetabular komponentin kenarından uygulanan hafif zorlamalar ile test edilebilir. Stabilitesi iyi ancak yanlış pozisyonda yerleştirilmiş komponentlerin dahi çıkarılması gerekebilir. İmplanta özgü olan asetabular komponent çıkarma aletleri ile ve protez-kemik arayüzüne giren kesiciler yardımıyla, asetabular komponentin kemikten güvenli ve hızlı bir şekilde çepeçevre ayrılması mümkün olmaktadır. Ancak, iyi sabitlenmiş bir implantın çıkarılması sırasında fazla kemik kaybından kaçınmak için dikkatli olunmalıdır. ${ }^{[33]}$

\section{TEDAVI SEÇENEKLERi}

\section{İmpaksiyon Greftleme ve Çimentolama}

İmpaksiyon grefleme, asetabular komponent revizyonu sırasında sık kullanılan bir tekniktir. Paprosky tip 3A defektlerde bu teknik önerilmektedir. İleri derecede medial yetmezliği olan defektlerde uygulanmamalıdır. ${ }^{[34,35]}$ Kansellöz greftlerin defektli bölgeye sıkı bir şekilde impakte edilmesi ve böylelikle kemik stoğunun artması prensibine dayanır. Sonrasında çimentolu polietilen asetabular komponent ile revizyon işlemi uygulanır. İmpaksiyon greftleme, daha basit kaviter defektler için uygun bir teknik olarak tanımlanmıştır. Ayrıca metal mesh yardımıyla, segmental veya kombine defektlerin cerrahi tedavisinde de kullanılabilir. Pelvik devamsızlığın görüldügü durumlarda ise metal mesh ile köprüleme yetersiz kalacağından, ilk önce bir plak yardımı ile pelvik devamsızlık fikse edilmeli, ardından impaksiyon greftleme uygulanmalıdır. Busch ve ark., asetabular impaksiyon greftlemenin uzun dönem sonuçları hakkında bir çalışma yayımlamışlardır. Çalışmaya, kaviter veya kombine asetabular defekti olan, impaksiyon greftleme ve çimentolu asetabular komponent ile revizyon uygulanan 42 hasta dâhil edilmiştir. Aseptik gevşemenin son nokta olarak kabul edildiği sağkalım analizlerinde, 20 yılda \%85, 25 yılda $\% 77$ sağkalım oranları elde edilmiştir. ${ }^{\left[{ }^{[6]}\right]}$ Baauw ve ark.'nın yayımladıkları meta-analizde, ortalama 5,2 yıllık takipte, aseptik gevşeme oranı $\% 8,8$, revizyon oranı ise $\% 6,4$ olarak bildirilmiştir. ${ }^{[5]}$

\section{Çimentosuz Poröz Kaplı Asetabular Komponent ile Rekonstrüksiyon}

Çimentosuz rekonstrüksiyon, revizyon kalça artroplastisi sırasında özellikle Paprosky tip 1 ve 2 defektler için sıklıkla tercih edilmektedir. ${ }^{[19]}$ Çimentosuz asetabular komponent ile revizyonun ele alındığı ve aseptik gevşemenin son nokta olarak kabul edildiği orta dönem takipli birçok çalışmada \%90'ın üzerinde sağkalım oranları bildirilmiştir. ${ }^{[37-40]}$ Bu konu ile ilgili en uzun takipli çalışmalardan biri, Della Valle ve ark. tarafından yayımlanmıştır. ${ }^{[41]}$ Yüz otuz sekiz kalçanın dâhil edildiği çalışmada, sadece bir kalça aseptik gevşeme nedeniyle revize edilmiştir. Aseptik gevşeme son nokta olarak ele alındığında, \%96 komponent sağkalımı tespit edilmiştir. Toplam 19 asetabular komponent, tekrarlayan instabilite, enfeksiyon veya femoral komponent sebebiyle revize edilmiştir. Bu sonuçlar diğer revizyon serileri ile tutarlı olmakla birlikte; revizyon cerrahilerinin, primer kalça artroplastisi ameliyatlarına göre kemik defekti, yumuşak doku sorunları ve bu gibi sebeplerle kalça biyomekaniğinin tam olarak restore edilememesinden dolayı, sonuçlarının daha kötü olduğu da bildirilmektedir. Revizyonda kullanılan çimentosuz asetabular rekonstrüksiyonda, kolon ve rim desteği yanı sıra asetabular vida tespitine de sıklıkla gereksinim duyulmaktadır. Günümüzde birçok firma, başlangıç stabilitesini artırmak ve defektli 
kemikte biyolojik tespit sağlamak adına, poröz kaplı komponentler geliştirmişlerdir. Poröz kaplı komponentler ile yapılan çalışmaların erken dönem sonuçlarında istenen biyolojik tespitin daha iyi elde edildiği gösterilmiştir. ${ }^{[42]}$ Daha büyük defektlerde ise 'jumbo' kaplar kullanılmaktadır. Erkeklerde $66 \mathrm{~mm}$, kadınlarda $62 \mathrm{~mm}$ ve üstü asetabular komponentler 'jumbo' olarak adlandırılır. ${ }^{[43]}$ Bunlar büyük defektlerde, defektin tam olarak doldurulmasını ve temas yüzeyini artırarak hem iyi bir tespit hem de anatomik rotasyon merkezinin oluşturulmasını sağlar. Buna karşııı, yetersiz kemik stoğuna sebep olacağı için, olası revizyon durumlarında teknik olarak zorluğa da yol açabilmektedir. ${ }^{[43]}$ Von Roth ve ark. ${ }^{[44]}$, jumbo kaplar ile 20 yıllık takipte \%83 sağkalım oranı bildirirken, Volpin ve ark.'nın ${ }^{[45]}$ yayımladığı çalışmada 10 yıllık takipte $\% 87,9$ sağkalım bildirilmiştir.

\section{Yapısal Allogreft ile Rekonstrüksiyon}

Yapısal allogreftler, komponent tespiti ve stabilitesini sağlamak için yeterli asetabular kemiğin bulunmadığı durumlarda tercih sebebi olabilmektedir. Kullanılan yapısal allogreftin amacı, çimentosuz asetabular komponent içine stabil bir kemik büyümesi sağlanana kadar asetabular komponente yapısal bir destek sağlamaktır. Yapısal allogreft, potansiyel revizyon ameliyatı durumunda artmış bir kemik stoğu yaratacağından dolayı, özellikle genç hasta popülasyonunda da tercih edilmektedir. Bunların yanı sıra, kullanılan allogreftlerin rezorpsiyon ve enfeksiyon riski olması sebebiyle, dolaylı olarak komponent gevşemesine yol açabileceği de akılda tutulmalıdır. Genel olarak allogreft, genç hastalarda ileride yeniden inşa edilmesinde kullanılabilecek artan kemik stoğu mevcudiyetiyle sonuçlanabileceği için tercih edilir. Revizyon ameliyatında kullanılan yapısal allogreftlerin orta dönem sonuçları birçok çalışmada değerlendirilmiştir. Bu çalışmalarda, greft tipi ve cerrahi teknik, klinik başarıyı belirlemede en önemli faktörler olarak karşımıza çıkmaktadır. Yine benzer şekilde DeWal ve ark., yapısal allogreft ile yapılan revizyon olgularının \%15'inde bileşenlerin gevşediğini bildirmişlerdir. ${ }^{[46]}$ Daha yakın dönemde, Lee ve ark.'nın yayımladığı, yapısal allogreftler ile revize edilmiş 74 hastayı kapsayan ve minimum beş yıl takipli geriye dönük bir çalışmada, aseptik gevşeme son nokta olarak kabul edildiğinde, 15 ve 20 yıllık komponent sağkalımlarının sırası ile $\% 67$ ve $\% 61$, greft sağkalımının \%81 olduğu bildirilmiştir. ${ }^{[4]}$ Yapısal allogrefler ile yapılan revizyon ameliyatlarının konu alındığı çalışmalarda, bunların orta ve uzun dönemde tatmin edici sonuçları olmasına rağmen, özellikle son dönemde artan poröz metal augmentlerin kullanımı ile birlikte popülaritesi azalmıştır.

\section{Modüler Poröz Kaplı Metal Augmentler ile Rekonstrüksiyon}

Görece yeni bir yaklaşım olan modüler metal augmentler, çimentosuz hemisferik asetabular komponentler ile birlikte kullanılır (Şekil 1). Bunlar Paprosky tip 3A, tip 3B ve pelvik devamsızlık durumunda tercih edilmektedir. ${ }^{[48,49]}$ Poröz metal augmentler tantalum veya titanyumdan üretilmektedir. Yüksek porozite $(\% 80)$ sayesinde, daha fazla bir sürtünme ve implant kemik ara yüzünde daha güçlü bir tespit elde edilmektedir. ${ }^{[50]}$ Modüler metal augmentler, asetabular komponentin kemik ile temasını artırarak, doğru pozisyonda komponent tespitine yardımcı olur. Hem asetabular komponent hem de poröz metal augmentler pelvise birbirlerinden ayrı olarak fikse edilmelerine rağmen, rutinde metal augment ve asetabular komponent birbirine çimento ile yapıştırılır. Metal augmentlerin amacı, yine yapısal allogreftlerde de olduğu gibi, asetabular komponent arasına sağlam bir kemik büyümesi gerçekleşene kadar yapısal bir destek sağlamaktır. Metal augmentler pelvise fikse edildikten sonra, gerekli görüldüğü takdirde kaviter defektler asetabular komponent implantasyonu öncesi morselize kemik grefti ile doldurulabilir. Daha sonra asetabular komponent uygun pozisyonda çakılır ve stabiliteyi artırmak adına, asetabular vidalar ile komponent pelvise fikse edilir. Sporer ve Paprosky tarafından yapılan, 28 hastanın yer aldığı ve ortalama takibin 3,1 yıl olduğu bir çalışmada, sadece bir hastada tekrarlayan instabilite nedeniyle yeniden revizyon uygulanmış, bunun dışında kalan diğer bütün hastalarda stabil bir yapı elde edilmiştir.[51] Van Kleunen ve ark. tarafından yapılan, 97 kalçanın (90 hasta) yer aldığı bir çalışmada ise Paprosky tip 2, $3 \mathrm{~A}$ ve $3 \mathrm{~B}$ defektlerine modüler metal augmentler ve çimentosuz asetabular komponentler ile revizyon uygulanmış ve ortalama 45 aylık bir takip süresinde herhangi bir aseptik gevşeme görülmediği bildirilmiştir. ${ }^{[52]}$

\section{Halka ve Kafes ile Rekonstrüksiyon}

Halka ve kafesler, özellikle mevcut kemik stoğunun yeterli olmadığı revizyon kalça artroplastisinde tercih sebebidir. Halkalar, superior asetabular çatıya destek oluşturmak için kullanılırken, anti-protrüzyo kafesler iliumdan iskiuma kadar uzanarak tüm asetabulumu korumak ve desteklemek için kullanılmaktadır (Şekil 2 ve 3 ). Halka ve kafeslerin öne çıkan en önemli avantajı, asetabular içliğin halka ve kafes pozisyonundan bağımsız olarak istenilen pozisyonda çimento ile dondurulabilmesi ve çimento ile beraber antibiyotiklerin lokal olarak kullanılabilmesidir. Bilinen en önemli dezavantajlarından birisi ise, biyolojik tespite izin 

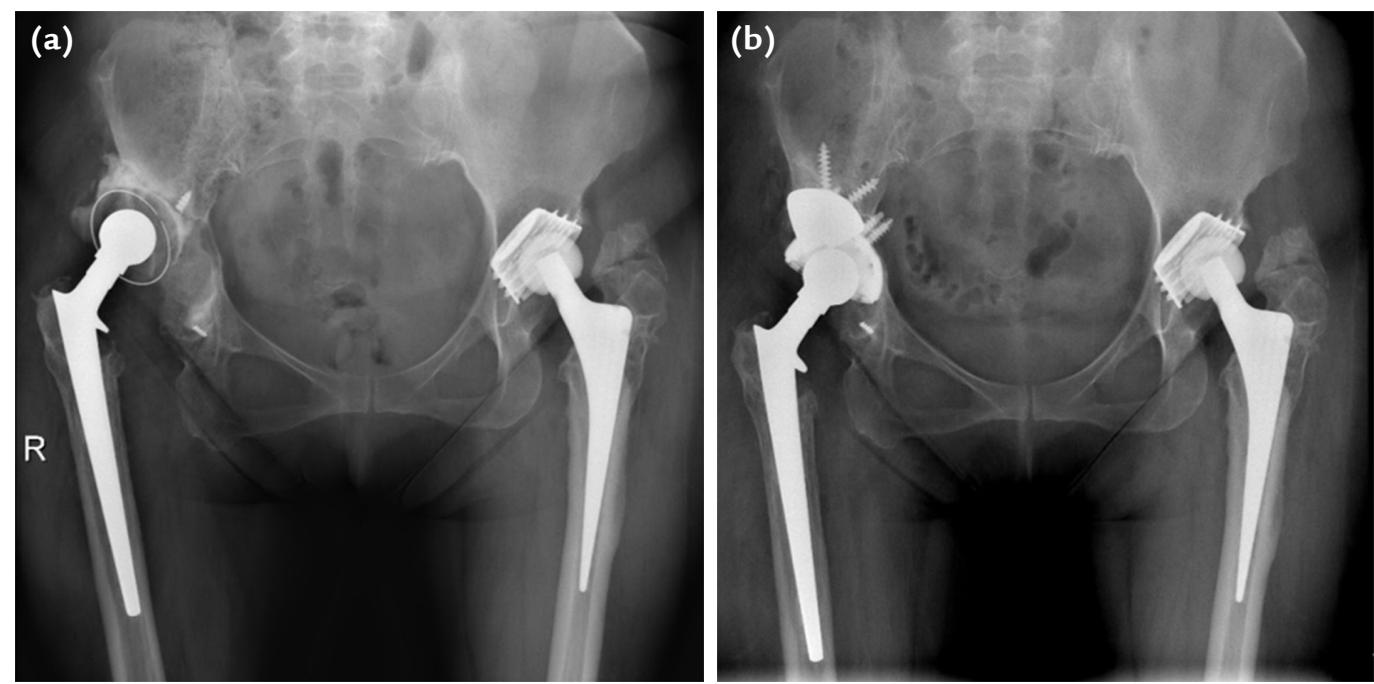

Şekil 1. a, b. Ameliyat öncesi pelvis ön-arka (AP) grafide Paprosky Tip 3A defekt (a). Defektin modüler poröz metal augment ve poröz kaplı hemisferik kap ile rekonstrükte edilmiş grafisi (b).
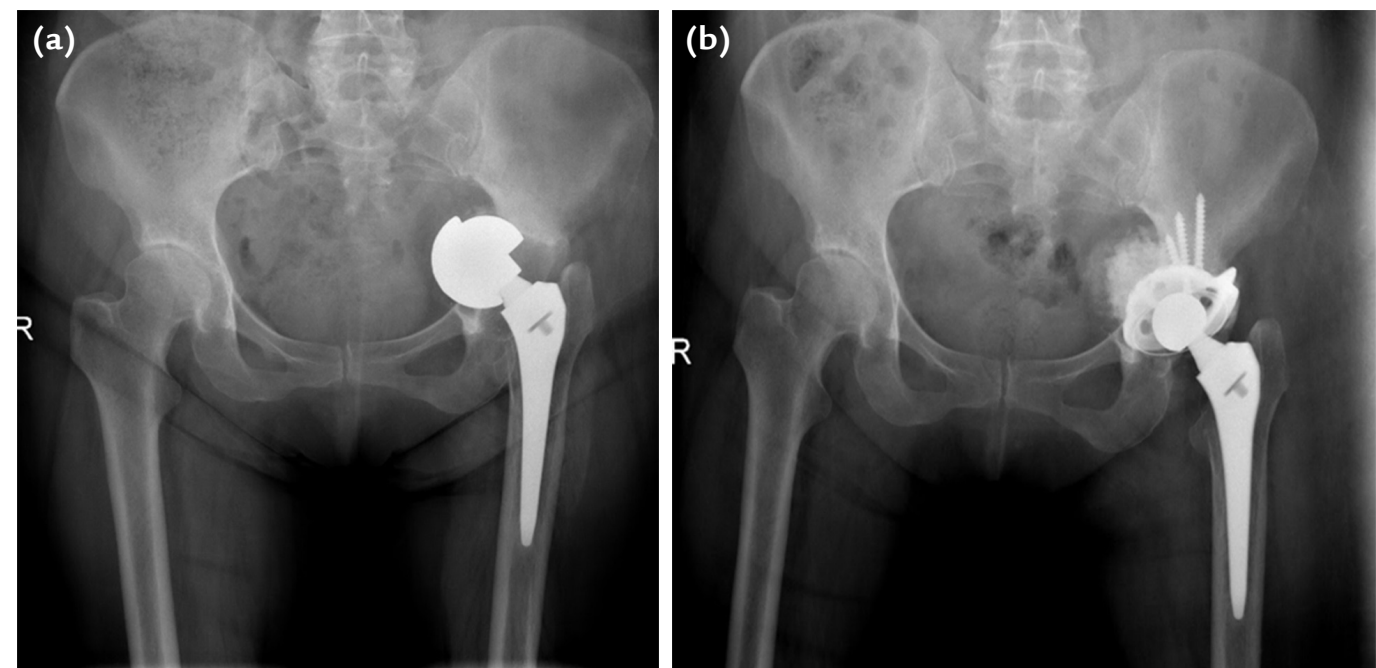

Şekil 2. a, b. Ameliyat öncesi grafide Paprosky tip 2C defekt (a). Defektin anti-protrüzyo kafes ile rekonstrükte edilmiş görüntüsü (b).
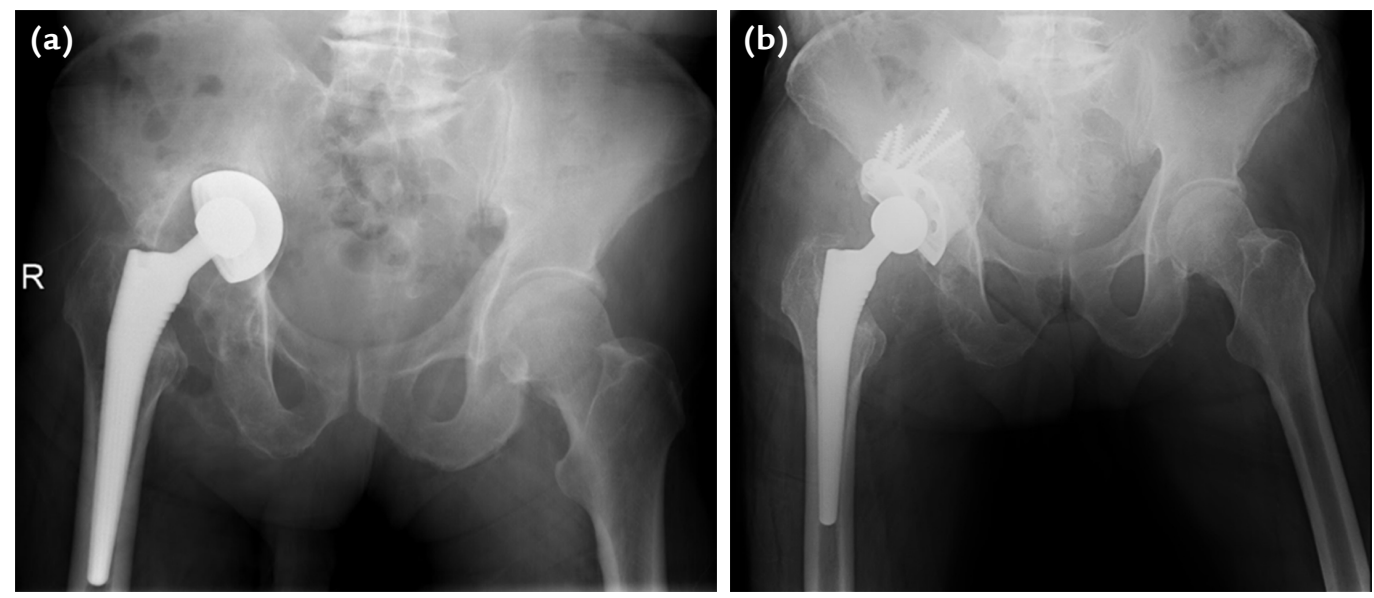

Şekil 3. a, b. Ameliyat öncesi pelvis ön-arka (AP) grafide tip 3B defekt (a). Defektin asetabular kafes yardımı ile rekonstrükte edilmiş grafisi (b). 
veren bir yapısı olmadığından dolayı, halka ve kafes yapılarının kırılması veya erken dönemde gevşemesidir. Bununla birlikte, halka ve kafes yapıları kırılsa ya da gevşese dahi, eğer kullanılan greftler konak kemik ile remodele olmuşsa, standart çimentosuz hemisferik asetabular komponent ile revizyon mümkün olmaktadır. Saydığımız dezavantajlar ve son dönemde artan metal augmentler ile yapılan revizyonlar sebebiyle halka ve kafes kullanımı giderek azalmaktadır. Literatürde yer alan çalışmalarda, halka ve kafeslerin orta dönem sonuçları tatmin edici olarak bulunmuştur. Zehntner ve Ganz'ın yayımladığı ve ortalama 7,2 yıl takipli olan 27 hastanın dâhil edildiği bir çalışmada, asetabular halka ile 10 yıllık sağkalımın $\% 80$ olduğu bildirilmiştir. ${ }^{[53]}$ Goodman ve ark.'nın yaptığı, 42 kalçanın Burch-Schneider asetabular kafesler ile revize edildiği ve takip süresinin 4,6 yıl olduğu çalışmada, aseptik gevşemenin son nokta olarak ele alındığı sağkalım analizinde $\% 76$ sağkalım rapor edilmiştir. ${ }^{[54]}$ Hacettepe Ortopedi ve Travmatoloji Ana Bilim Dalında yapılan, 54 hasta ve 56 kalçanın dâhil edildiği bir çalışmada, beş kalçada re-revizyon uygulanmış olup \%91,5 sağkalım oranı elde edilmiştir. Hospital for Special Surgery (HSS) skorlarında ise ameliyat öncesi 27,9 olan skor, sonrası son takipte ortalama 45,9'a yükselmiştir. Bu sonuçlarla birlikte, kafes ile asetabular rekonstrüksiyonun uzun dönem sonuçlarının başarılı olduğu bildirilmiştir. ${ }^{[55]}$ Quarto ve ark.'nın yaptı̆̆ı çalışmaya, impaksiyon greftleme ve kafes uygulanan 40 kalça dâhil edilmiştir. Ortalama 14,3 yıllık takipte yüksek sağkalım oranları elde edilmiş ve bu sonuçla birlikte, impaksiyon greftleme ve kafes ile asetabular rekonstrüksiyonunun uzun dönemde başarılı sonuçları olduğu bildirilmiştir. ${ }^{[56]}$

\section{Oblong Kap ile Rekonstrüksiyon}

Oblong asetabular kaplar konak kemiğinde mekanik stabilite elde etmek için tasarlanmıştır. Oblong asetabular kaplar, sıklıkla geniş superior segmental kemik defektlerinde ve hemisferik kabın yetersiz olduğu defektlerde tercih edilen komponentlerdir. ${ }^{[57-59]}$ Bilobe (bilobed) oblong kap, longitudinal oblong kap (longitudinal oblong revision LOR) ve BOFOR kap olmak üzere üç tipi vardır. ${ }^{[59]}$ Bu teknikle ilgili birkaç uzun dönem veri mevcuttur. Landor ve ark., yakın zamanda, Paprosky tip 2B ve $3 \mathrm{~A}$ defektlerde kullanılan iki farklı oblong asetabular kapın orta dönem sonuçlarını yayımlamışlardır. İki farklı grup için, son takipte sırası ile $\% 5,3$ ve $\% 13,5$ aseptik gevşeme oranları bildirilmiştir. ${ }^{60]}$ Oblong kapların belirli kemik defektlerinin yönetimi için revizyonda sınırlı bir rolü olmasına rağmen, modüler poröz metal augmentlerin yaygınlaşması ile kullanımları artmaktadır.

\section{Kap-Kafes ile Rekonstrüksiyon}

Kap-kafes rekonstrüksiyonu görece yeni bir teknik olarak karşımıza çıkmaktadır. Nehme ve ark. tarafından tanımlanan bu hibrid teknikte, hem biyolojik tespiti sağlamak hem de mekanik stabiliteyi artırmak adına, poröz kaplı çimentosuz asetabular komponent ile ilio-iskial kafes birlikte kullanılmaktadır. ${ }^{[48]}$ Kap-kafes tekniği, sadece Paprosky tip 3A ve 3B defektlerde değil, pelvik devamsızı̆ı̆ın eşlik ettiği asetabular kemik defektlerinin rekonstrüksiyonunda da kullanılabilmektedir. Bu teknikte ilk olarak, çimentosuz asetabular komponent metal augmentlerin de yardımı ile konak kemiğe fikse edilir. Ardından, pelvik devamsızlığın her iki tarafına uzanan bir anti-protrüzyo kafes asetabular komponentin içine yerleştirildikten sonra fikse edilir. Kafes ile birlikte elde edilen başlangıç stabilitesi çimentosuz poröz kaplı asetabular komponentin biyolojik tespiti için zaman sağlamış olur. ${ }^{[61]}$ Kosashvili ve ark.'nın, pelvik devamsızlığı olan 26 kalçada uyguladığı kap-kafes rekontrüksiyonunun konu alındığı bir çalışmada, 23 kalçada son takipte herhangi bir klinik ve radyolojik gevşeme bulgusu tespit edilmemiştir. Iki yıllık takipte ise Harris kalça skoru 46,6'dan 76,6'ya yükselmiştir. Pelvik devamsızlığın eşlik ettiği asetabular kemik defektlerinin rekonstrüksiyonunda kap-kafes rekonstrüksiyonunun güvenli bir seçenek olarak kullanılabileceği sonucu raporlanmıştır. ${ }^{[62]}$ Alfaro ve Fernández, metal augmentler ve çimentosuz asetabular komponentler ile revize edilen 13 Paprosky tip $3 \mathrm{~A}$ ve altı Paprosky tip 3B hastasını değerlendirmişlerdir. On dokuz hastanın beşinde pelvik devamsızlık tespit edilmiş olup bu hastalarda kap-kafes rekonstrüksiyonu uygulanmıştır. Ortalama 26 aylık takip süresinde aseptik gevşemeye bağlı herhangi bir başarısızlık tespit edilmemiştir. ${ }^{[63]}$ Kap-kafes rekonstrüksiyonu ile erken dönem sonuçları umut verici olmasına rağmen, uzun dönem sonuçlarının çalışılması gerekmektedir.

\section{Triflange Asetabular Komponent ile Rekonstrüksiyon}

Kişiye özel üretilen triflange asetabular kaplar, üç boyutlu rekontrüksiyonlu pelvis tomografisi kullanılarak geliştirilen plastik pelvis modelleri kullanılarak üretilmektedir. Ayrıca bu plastik modeller ortopedi ve travmatoloji uzmanının defekti üç boyutlu bir şekilde anlamasına ve ameliyata hazırlanarak girmesine de olanak sağlamaktadır. Triflange kaplar, pelvik devamsızlık durumlarında, halka-kafes yapılarından daha fazla olacak şekilde defekti tamamen dolduran rijit bir tespit sağlamakta ve pelvik devamsızlığın daha hızlı iyileşmesini sağlamaktadır. Triflange kapların orta dönem takiplerinde mükemmel sonuçlar bildirilmiştir. Dennis ve ark.'nın, triflange kap uygulanmış, ortalama dört yıllık takibi olan ve bir hastanın revize edildiği 24 hastayı 
kapsayan geriye dönük çalışmalarında, toplam üç hastada radyolojik olarak aseptik gevşeme tespit edilmiştir. ${ }^{[64]}$ DeBoer ve ark. ise yaygın asetabular kemik kaybı ve pelvik devamsızlığı olan 20 hastaya triflange kap ile revizyon uygulamışlardır. Ortalama 10 yıllık takipte, 18 hastada pelvik devamsızlığın iyileştiği tespit edilmiştir. ${ }^{[65]}$ Triflange kaplarla, pelvik devamsızlığın eşlik ettiği şiddetli asetabular kemik defekti olan hastalarda düşük gevşeme oranları ve yüksek pelvik devamsızlık iyileşme oranları ile mükemmel orta dönem sonuçlar bildirilmiştir. ${ }^{[65]}$ Bununla beraber, yüksek maliyet oranları ve konak kemikteki rijit metal yapının bunun üzerindeki uzun dönem sonuçları hakkında endişeler de olduğu göz önünde bulundurulmalıdır.

\section{SONUÇ}

Total kalça artroplastisinde revizyon cerrahisi, normal kalça biyomekaniğini yeniden oluşturmayı ve uzun dönem stabil bir tespiti amaçlamalıdır. Revizyon cerrahisinde, konak kemik kalitesi ve olası kemik defektleri gibi sebeplerden dolayı, mekanik stabilite ve komponent ile kemik arasında sağlıklı bir osteo-integrasyon sağlamak çoğu zaman zordur. Son zamanlarda ortopedik implantlardaki gelişmeler, asetabular revizyon cerrahisinde bize birçok olanak sunmaktadır. Bu gelişmelere rağmen, ortopedi ve travmatoloji uzmanları arasında, asetabulum revizyonunda hangi tekniğin diğerine üstün olduğuna dair tam bir uzlaşı henüz yoktur. Başarılı bir sonuç için, ayrıntılı bir ameliyat öncesi planlama gereklidir. Asetabular kemiğin kalitesi ve olası defektlerin yeri ve büyüklüğü mutlaka iyi irdelenmelidir. Paprosky sınıflaması, en yaygın kullanılan asetabular kemik defekti sınıflaması olarak, asetabular kemik defektini iyi bir şekilde anlamamızda ve olası cerrahi rekonstrüksiyon seçeneğini belirlememizde bize yardımcı olmaktadır. Genel anlamda; defektin yeri, büyüklüğü, pelvik devamsızlık olup olmaması, implantların uygunluğu ve cerrah deneyimine bağlı olarak rekonstrüksiyon seçenekleri bu sınıflamaya göre belirlenmektedir. Asetabular kemik defektlerinin birçoğu çimentosuz hemisferik asetabular komponentler ile revize edilebilmektedir. Bununla birlikte, Paprosky tip $3 \mathrm{~A}$ ve $3 \mathrm{~B}$ gibi yaygın ve büyük asetabular kemik defektlerin bulunduğu revizyon ameliyatlarında, sadece çimentosuz komponentlerin kullanımı yetersiz kalabilmektedir. Bu gibi durumlarda, ayrıntılı bir ameliyat öncesi planlama ile yapısal kemik defektlerini iyi tahlil etmek, stabil bir komponent tespiti ve başarılı bir sonuç için gereklidir. Yapısal allogreft, modüler poröz kaplı metal augmentler, kap-kafes tekniği ya da triflange asetabular komponentler ve asetabular kemik defektine yönelik rekonstrüksiyon seçenekleri ile revizyon cerrahisinin yapılması mümkündür.

\section{KAYNAKLAR}

1. Ethgen $O$, Bruyère $O$, Richy $F$, Dardennes $C$, Reginster $J Y$. Health-related quality of life in total hip and total knee arthroplasty. A qualitative and systematic review of the literature. J Bone Joint Surg Am 2004;86(5):963-74. Crossref

2. Pivec R, Johnson AJ, Mears SC, Mont MA. Hip arthroplasty. Lancet 2012;380(9855):1768-77. Crossref

3. Mäkelä KT, Eskelinen A, Pulkkinen P, Paavolainen P, Remes V. Total hip arthroplasty for primary osteoarthritis in patients fiftyfive years of age or older. An analysis of the Finnish arthroplasty registry. J Bone Joint Surg Am 2008;90(10):2160-70. Crossref

4. Kurtz SM, Ong KL, Lau E, Bozic KJ. Impact of the economic downturn on total joint replacement demand in the United States: updated projections to 2021. J Bone Joint Surg Am 2014;96(8):624-30. Crossref

5. Baauw M, van Hooff ML, Spruit M. Current Construct Options for Revision of Large Acetabular Defects: A Systematic Review. JBJS Rev 2016;4(11):e2. Crossref

6. Jain S, Grogan RJ, Giannoudis PV. Options for managing severe acetabular bone loss in revision hip arthroplasty. A systematic review. Hip Int 2014;24(2):109-22. Crossref

7. Howie DW, Neale SD, Martin W, Costi K, Kane T, Stamenkov R, Findlay DM. Progression of periacetabular osteolytic lesions. J Bone Joint Surg Am 2012;94(16):e1171-6. Crossref

8. Nieminen J, Pakarinen T-K, Laitinen M. Orthopaedic reconstruction of complex pelvic bone defects. Evaluation of various treatment methods. Scand J Surg 2013;102(1):36-41. Crossref

9. Parvizi J, Tan TL, Goswami K, Higuera C, Della Valle C, Chen AF, Shohat N. The 2018 Definition of Periprosthetic Hip and Knee Infection: An Evidence-Based and Validated Criteria. J Arthroplasty 2018;33(5):1309-14.e2. Crossref

10. Ghanem E, Parvizi J, Burnett RS, Sharkey PF, Keshavarzi $\mathrm{N}$, Aggarwal A, Barrack RL. Cell count and differential of aspirated fluid in the diagnosis of infection at the site of total knee arthroplasty. J Bone Joint Surg Am 2008;90(8):163743. Crossref

11. Della Valle CJ, Sporer SM, Jacobs JJ, Berger RA, Rosenberg AG, Paprosky WG. Preoperative testing for sepsis before revision total knee arthroplasty. J Arthroplasty 2007;22(6 Suppl 2):90-3. Crossref

12. Fryhofer GW, Ramesh S, Sheth NP. Acetabular reconstruction in revision total hip arthroplasty. J Clin Orthop Trauma 2020;11(1):22-8. Crossref

13. Southwell DG, Bechtold JE, Lew WD, Schmidt AH. Improving the detection of acetabular osteolysis using oblique radiographs. J Bone Joint Surg Br 1999;81(2):289-95. Crossref

14. Egawa H, Powers CC, Beykirch SE, Hopper RH Jr, Engh CA Jr, Engh CA. Can the volume of pelvic osteolysis be calculated without using computed tomography? Clin Orthop Relat Res 2009;467(1):181-7. Crossref

15. Hall A, Eilers M, Hansen R, Robinson BS, Maloney WJ, Paprosky WG, Ries MD, Saleh KJ. Advances in acetabular reconstruction in revision total hip arthroplasty: maximizing function and outcomes after treatment of periacetabular osteolysis around the well-fixed shell. J Bone Joint Surg Am 2013;95(18):1709-18. Crossref

16. Cahir JG, Toms AP, Marshall TJ, Wimhurst J, Nolan J. CT and MRI of hip arthroplasty. Clin Radiol 2007;62(12):1163-71;discussion 1172-3. Crossref

17. Puri L, Wixson RL, Stern SH, Kohli J, Hendrix RW, Stulberg SD. Use of helical computed tomography for the assessment of acetabular osteolysis after total hip arthroplasty. J Bone Joint Surg Am 2002;84(4):609-14. Crossref 
18. Sheth NP, Nelson CL, Springer BD, Fehring TK, Paprosky WG. Acetabular bone loss in revision total hip arthroplasty: evaluation and management. J Am Acad Orthop Surg 2013;21(3):128-39. Crossref

19. Sporer SM, Paprosky WG, O'Rourke MR. Managing bone loss in acetabular revision. Instr Course Lect 2006;55:28797. https://pubmed.ncbi.nlm.nih.gov/16958464/

20. Fehring TK, Guilford WB, Baron J. Assessment of intrapelvic cement and screws in revision total hip arthroplasty. J Arthroplasty 1992;7(4):509-18. Crossref

21. Sporer SM. How to do a revision total hip arthroplasty: revision of the acetabulum. J Bone Joint Surg Am 2011;93(14):135966. Crossref

22. Archibeck MJ, Rosenberg AG, Berger RA, Silverton CD. Trochanteric osteotomy and fixation during total hip arthroplasty. J Am Acad Orthop Surg 2003;11(3):163-73. Crossref

23. Younger TI, Bradford MS, Magnus RE, Paprosky WG. Extended proximal femoral osteotomy. A new technique for femoral revision arthroplasty. J Arthroplasty 1995;10(3):32938. Crossref

24. Johanson NA, Driftmier KR, Cerynik DL, Stehman CC. Grading acetabular defects: the need for a universal and valid system. J Arthroplasty 2010;25(3):425-31. Crossref

25. Gustilo RB, Pasternak HS. Revision total hip arthroplasty with titanium ingrowth prosthesis and bone grafting for failed cemented femoral component loosening. Clin Orthop Relat Res 1988;(235):111-9. Crossref

26. D'Antonio JA, Capello WN, Borden LS, Bargar WL, Bierbaum BF, Boettcher WG, Steinberg ME, Stulberg SD, Wedge $\mathrm{JH}$. Classification and management of acetabular abnormalities in total hip arthroplasty. Clin Orthop Relat Res 1989;(243):126-37. Crossref

27. D'Antonio JA. Periprosthetic bone loss of the acetabulum. Classification and management. Orthop Clin North Am 1992;23(2):279-90. https://pubmed.ncbi.nlm.nih. gov/1570140/

28. Gross AE, Catre M, Garbuz DS, Allan DG, Stockley I. Bone grafts in hip replacement surgery. The pelvic side. Orthop Clin North Am 1993;24(4):679-95. Crossref

29. Paprosky WG, Perona PG, Lawrence JM. Acetabular defect classification and surgical reconstruction in revision arthroplasty. A 6-year follow-up evaluation. J Arthroplasty 1994;9(1):33-44. Crossref

30. Saleh KJ, Holtzman J, Gafni ASaleh L, Jaroszynski G, Wong P, Woodgate I, Davis A, Gross AE. Development, test reliability and validation of a classification for revision hip arthroplasty. J Orthop Res 2001;19(1):50-6. Crossref

31. Gozzard C, Blom A, Taylor A, Smith E, Learmonth I. A comparison of the reliability and validity of bone stock loss classification systems used for revision hip surgery. J Arthroplasty 2003;18(5):638-42. Crossref

32. Campbell DG, Garbuz DS, Masri BA, Duncan CP. Reliability of acetabular bone defect classification systems in revision total hip arthroplasty. J Arthroplasty 2001;16(1):83-6. Crossref

33. Maloney WJ, Herzwurm P, Paprosky W, Rubash HE, Engh CA. Treatment of pelvic osteolysis associated with a stable acetabular component inserted without cement as part of a total hip replacement. J Bone Joint Surg Am 1997;79(11):1628-34. Crossref

34. Buttaro MA, Comba F, Pusso R, Piccaluga F. Acetabular revision with metal mesh, impaction bone grafting, and a cemented cup. Clin Orthop Relat Res 2008;466(10):248290. Crossref
35. Garcia-Cimbrelo E, Cruz-Pardos A, Garcia-Rey E, OrtegaChamarroJ. The survival and fate of acetabular reconstruction with impaction grafting for large defects. Clin Orthop Relat Res 2010;468(12):3304-13. Crossref

36. Busch VJJF, Gardeniers JWM, Verdonschot $N$, Slooff TJJH, Schreurs BW. Acetabular reconstruction with impaction bone-grafting and a cemented cup in patients younger than fifty years old: a concise follow-up, at twenty to twentyeight years, of a previous report. J Bone Joint Surg Am 2011;93(4):367-71. Crossref

37. Templeton JE, Callaghan JJ, Goetz DD, Sullivan PM, Johnston RC. Revision of a cemented acetabular component to a cementless acetabular component. A ten to fourteen-year follow-up study. J Bone Joint Surg Am 2001;83(11):1706-11. Crossref

38. Jamali AA, Dungy DS, Mark A, Schule S, Harris WH. Isolated acetabular revision with use of the Harris-Galante Cementless Component. Study with intermediate-term follow-up. J Bone Joint Surg Am 2004;86(8):1690-7. Crossref

39. Hallstrom BR, Golladay GJ, Vittetoe DA, Harris WH. Cementless acetabular revision with the Harris-Galante porous prosthesis. Results after a minimum of ten years of follow-up. J Bone Joint Surg Am 2004;86(5):1007-11. Crossref

40. Jones CP, Lachiewicz PF. Factors influencing the longer-term survival of uncemented acetabular components used in total hip revisions. J Bone Joint Surg Am 2004;86(2):342-7. Crossref

41. Della Valle CJ, Berger RA, Rosenberg AG, Galante JO. Cementless acetabular reconstruction in revision total hip arthroplasty. Clin Orthop Relat Res 2004;(420):96-100. Crossref

42. Meneghini RM, Ford $\mathrm{KS}$, McCollough $\mathrm{CH}$, Hanssen $\mathrm{AD}$, Lewallen DG. Bone remodeling around porous metal cementless acetabular components. J Arthroplasty 2010;25(5):741-7. Crossref

43. Whaley AL, Berry DJ, Harmsen WS. Extra-large uncemented hemispherical acetabular components for revision total hip arthroplasty. J Bone Joint Surg Am 2001;83(9):1352-7. Crossref

44. von Roth P, Abdel MP, Harmsen WS, Berry DJ. Uncemented jumbo cups for revision total hip arthroplasty: a concise follow-up, at a mean of twenty years, of a previous report. J Bone Joint Surg Am 2015;97(4):284-7. Crossref

45. Volpin A, Konan S, Biz C, Tansey RJ, Haddad FS. Reconstruction of failed acetabular component in the presence of severe acetabular bone loss: a systematic review. Musculoskelet Surg 2019;103(1):1-13. Crossref

46. Dewal H, Chen F, Su E, Di Cesare PE. Use of structural bone graft with cementless acetabular cups in total hip arthroplasty. J Arthroplasty 2003;18(1):23-8. Crossref

47. Lee PT, Raz G, Safir OA, Backstein DJ, Gross AE. Longterm results for minor column allografts in revision hip arthroplasty. Clin Orthop Relat Res 2010;468(12):3295303. Crossref

48. Nehme A, Lewallen DG, Hanssen AD. Modular porous metal augments for treatment of severe acetabular bone loss during revision hip arthroplasty. Clin Orthop Relat Res 2004;429:201-8. Crossref

49. Weeden $\mathrm{SH}$, Schmidt $\mathrm{RH}$. The use of tantalum porous metal implants for Paprosky $3 \mathrm{~A}$ and 3B defects. J Arthroplasty 2007;22(6 Suppl 2):151-5. Crossref

50. Bobyn JD, Stackpool GJ, Hacking SA, Tanzer M, Krygier JJ. Characteristics of bone ingrowth and interface mechanics of a new porous tantalum biomaterial. J Bone Joint Surg Br 1999;81(5):907-14. Crossref 
51. Sporer SM, Paprosky WG. The use of a trabecular metal acetabular component and trabecular metal augment for severe acetabular defects. J Arthroplasty 2006;21(6 Suppl 2):83-6. Crossref

52. Van Kleunen JP, Lee G-C, Lementowski PW, Nelson CL, Garino JP. Acetabular revisions using trabecular metal cups and augments. J Arthroplasty 2009;24(6 Suppl):64-8. Crossref

53. Zehntner MK, Ganz R. Midterm results (5.5-10 years) of acetabular allograft reconstruction with the acetabular reinforcement ring during total hip revision. J Arthroplasty 1994;9(5):469-79. Crossref

54. Goodman S, Saastamoinen $H$, Shasha $N$, Gross A. Complications of ilioischial reconstruction rings in revision total hip arthroplasty. J Arthroplasty 2004;19(4):436-46. Crossref

55. Akel i, Cağlar Ö, Tokgözoğlu AM, Atilla B. Titanium cage reconstruction of acetabular defects in revision hip arthroplasty results in favourable outcomes: up to 17 years follow-up. Hip Int 2020;30(5):617-21. Crossref

56. Quarto E, Zanirato A, Santolini F, Formica M. Bone impaction grafting and anti-protrusio cages in high-grade acetabular defects: a 22-year single centre experience. Arch Orthop Trauma Surg 2021. [Online ahead of print] Crossref

57. García-Rey E, Fernández-Fernández R, Durán D, Madero R. Reconstruction of the rotation center of the hip after oblong cups in revision total hip arthroplasty. J Orthop Traumatol 2013;14(1):39-49. Crossref

58. Köster G, Rading S. Revision of failed acetabular components utilizing a cementless oblong cup: an average 9-year followup study. Arch Orthop Trauma Surg 2009;129(5):603-8. Crossref
59. Desai AS, Dramis A, Board TN, Hekal W, Farhan MJ. Acetabular revision surgery with the uncemented oblong BOFOR Cup -early to midterm results. Hip Int 2012;22(3):280-5. Crossref

60. Landor I, Vavrík P, Jahoda D, Pokorný D, Popelka S, Sosna A. Oválné implantáty $v$ problematice revizí totálních náhrad kycelního kloubu [Oblong implants for revision total hip arthroplasty]. Acta Chir Orthop Traumatol Cech 2009;76(6):462-72. https://achot.actavia.cz/magno/ ach/2009/mn6.php

61. Konan S, Duncan CP, Masri BA, Garbuz DS. The cup-cage reconstruction for pelvic discontinuity has encouraging patient satisfaction and functional outcome at median 6-year follow-up. Hip Int 2017;27(5):509-13. Crossref

62. Kosashvili $Y$, Backstein D, Safir O, Lakstein D, Gross AE. Acetabular revision using an anti-protrusion (ilio-ischial) cage and trabecular metal acetabular component for severe acetabular bone loss associated with pelvic discontinuity. J Bone Joint Surg Br 2009;91(7):870-6. Crossref

63. Alfaro JJB, Fernández JS. Trabecular Metal buttress augment and the Trabecular Metal cup-cage construct in revision hip arthroplasty for severe acetabular bone loss and pelvic discontinuity. Hip Int 2010;20 Suppl 7:S119-27. Crossref

64. Dennis DA. Management of massive acetabular defects in revision total hip arthroplasty. J Arthroplasty 2003;18(3 Suppl 1):121-5. Crossref

65. DeBoer DK, Christie MJ, Brinson MF, Morrison JC. Revision total hip arthroplasty for pelvic discontinuity. J Bone Joint Surg Am 2007;89(4):835-40. Crossref 